\title{
MALE RUFF DISPLAYS TO THREE FEMALES NEAR CHURCHILL, MANITOBA
}

JOHN D. REYNOLDS, Department of Biology, Queen's University, Kingston, Ontario. K7L 3N6

The Ruff breeds in northern Europe and Asia from the British Isles to Southeastern Siberia. ${ }^{\prime}$ In North America this shorebird is a scarce but regular spring and fall migrant. Its pattern of regular occurrence has prompted speculation by many that Ruffs may breed on this continent. ${ }^{5}$ Confirmation was obtained in 1976 when Gibson ${ }^{3}$ discovered a nest containing four eggs in Alaska. [This isolated nesting remains the only breeding record of the Ruff in the New World.]

On 26 June 1983, Susan Alton and I observed a male Ruff in nuptial plumage briefly displaying to three females in northern Manitoba. The sighting was on the southeast side of Norton Lake, $3 \mathrm{~km}$ west of the Queen's University Tundra Biology Station at La Pérouse Bay, $40 \mathrm{~km}$ east of Churchill $\left(58^{\circ} 24 \mathrm{~N}, 94^{\circ} 24 \mathrm{~W}\right)$. The birds appeared quite suddenly, flying low over the tundra in a tight cluster. The females were in the lead, the male behind. They landed for about 10 seconds $30 \mathrm{~m}$ from us. The male ran appoximately $2 \mathrm{~m}$ in a hunched, almost horizontal posture, toward the females. This posture was similar to the "halfsquat" described by van Rhijn. ${ }^{8} \mathrm{He}$ then stopped, drew upright for about one second (apparently the "tiptoe"8 posture), and tilted his head and neck forward so that his body was horizontal. He erected his white "ruff" (collar) and confronted the females for about 3 to 5 seconds. Then

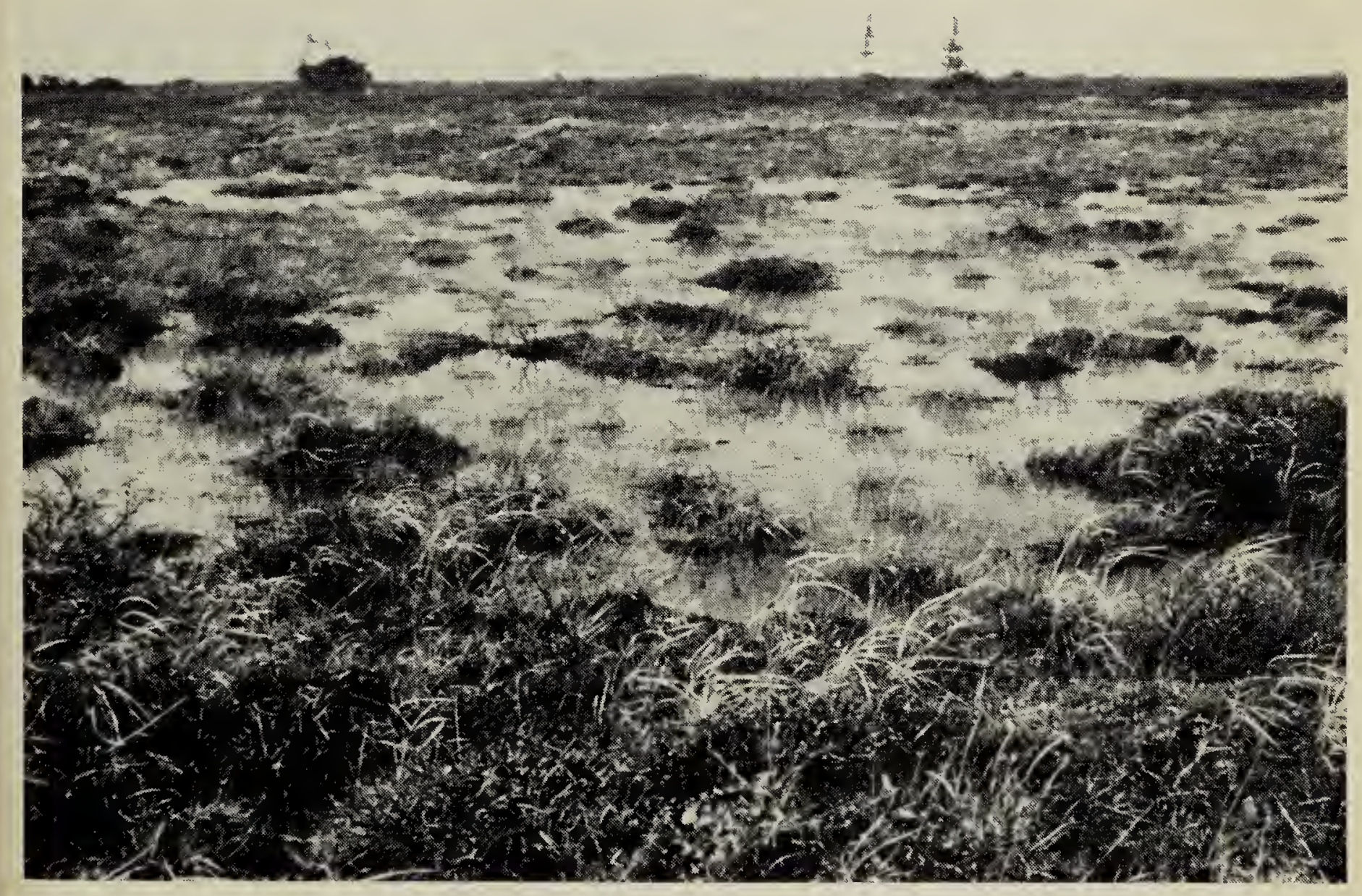

Figure 1. Ruff habitat, Norton Lake, Manitoba

J.D. Reynolds 
all four suddenly flew south, the females again in the lead, until they were out of sight.

The combination of the brevity of the sighting, and our state of shock at the time, make the following description less detailed than we would have liked. The male was dark blackish-orange on the lower back and head, with a spectacular white ruff, and white ear tufts. His bill and forehead were a very prominent orange. The females were smaller than the male, approximately the same size as Pectoral Sandpipers, although they had a more "drawn out" appearance. The upper breast had an even, buffy wash; not the fine streaking of Pectorals. The brownish colouration gave way gradually to white beneath; not cut off distinctly as in Pectorals. The upper-parts were tan and the back had a "scaly" appearance. The medium-length bill and longish legs appeared to be dark.

The habitat (Figure 1) consisted of raised hummocks dominated by Dwarf Willow (Salix brachycarpa), reindeer moss (Cladonia spp.), , Alpine Bearberry (Arcotstaphylos alpina), and sedges (Carex aquatilis and others). There were also a few clumps of stunted Black Spruce (Picea mariana), and some scattered Dwarf Birch (Betula glandulosa) and Mountain Avens (Dryas integrifolia). Due to a late spring melt and proximity to Norton Lake, which was about 300 m away, most of the area was flooded, with only ridges and hummocks dry.

The area was not visited again during the following week. However, on 2 July, six days after our sighting, Ray Alisauskas and Terry Quinney observed a similarlyplumaged male about $5 \mathrm{~km}$ to the north. The bird was seen only briefly from a moving track vehicle $60 \mathrm{~m}$ away. It bent its head low to the ground and erected its white ruff as in the half-squat posture noted on 26 June, and was accompanied by two or three drably plumaged shorebirds which may have been females. The habitat was somewhat drier than the Nor- ton Lake area and we judged it to be more suitable for nesting. On 8 July we searched this general area but were unsuccessful in locating any adults.

There are four previous records of Ruffs in Manitoba; three of these are from Churchill. An adult of undetermined sex was seen there on 23 June $1970^{6}$, an adult male was photographed there from 23 to 24 June 1974 and a subadult male was photographed there on 17 June 1978 (T. Burke, T. Dabis, m ob; R. Koes, pers. comm.). The remaining Manitoba record was of an adult male at Oak Hammock Marsh in southern Manitoba. It was present from 1 to 6 May 1983, photographed by $P$. Taylor and seen by many others (R. Koes, pers. comm.).

The dates of occurrence of Ruffs in the Churchill area coincide with the average time of early incubation for most of the local species of shorebirds. Habitat which appears to be suitable for breeding is abundant in the Churchill area and, indeed, throughout much of the low arctic. The birds seen in 1983 could have been migrants travelling further north. However, the observations of breeding display and sightings six days apart during the local shorebird breeding season, suggest against this. The birds may have been nonbreeders, simply "going through the motions". Ruffs are well known for their elaborate leks, where males of various status and plumages compete for females on small courtship territories. The plumage and postures of the male in the Norton Lake area were typical of "satellite" males which do not defend territories themselves, but use territories of dark-tufted "residents" males. ${ }^{4}{ }^{8}$ In general, this highly structured social system may hinder breeding in new areas. However, the mating system may be more flexible in areas where adults occur in low density.

If Ruffs do indeed breed in the eastern low arctic, the main difficulty in confirming it will be the vast area of virtually unexplored but apparently suitable habitat. 
This concept was illustrated well by the 1980 nestings of the rare Ross' Gull, ${ }^{2}$ which could easily have been overlooked had the birds not chosen nesting sites within one kilometre of the main road in Churchill. With increased coverage of the Churchill area, it will be interesting to see whether concrete evidence of breeding by Ruffs is obtained.

\section{Acknowledgements}

These observations were made during a study of Red-necked Phalarope ecology, funded by the Canadian Wildlife Service, a Canadian Department of Indian and Northern Affairs Training Grant, and Queen's University. I thank Susan Alton, Terry Quinney and Ray Alisauskas for their descriptions of the Ruffs. Rudolph Koes kindly provided records of Ruffs in Manitoba, and Kathy Martin and Doug McRae provided helpful comments on the manuscript.

'AMERICAN ORNITHOLOGISTS' UNION. 1983. Check-list of North American
Birds. Sixth edition. Washington, D.C.

${ }^{2}$ CHARTIER, B. and F. COOKE. 1980. Ross' Gulls (Rhodostethia rosea) nesting at Churchill, Manitoba, Canada. Amer. Birds 34:839-841.

${ }^{3}$ GIBSON, D.D. 1977 . First North American nest and eggs of the Ruff. Western Birds 8:25-26.

${ }^{4}$ HOGAN-WARBURG, A.J. 1966. Social behaviour of the Ruff, Philomachus pugnax(L.). Ardea 54:109-225.

${ }^{5}$ PEAKALL, D.B. 1965. The status of the Ruff in North America. Wilson Bull. 77:294-296.

6 PITTAWAY, R. and R.W. NERO. 1971. Recent bird notes of interest for Churchill, Manitoba. Blue Jay 29(2):60-63.

${ }^{7}$ RIBBLE, B.A. 1975. Ruff in Churchill, Manitoba. Blue Jay 33(3):178-179.

${ }^{8}$ VAN RHIJN, J.G. 1973. Behavioural dimorphism in male Ruffs. Philomachus pugnax (L.). Behaviour 47:153-229.

\section{LONG-TAILED JAEGER IN SOUTHERN MANITOBA}

GRAHAM J. CRAWSHAW*, Metropolitan Toronto Zoo, P.O. Box 280 West Hill, Ontario. M1E 4R5

The Long-tailed Jaeger is one of three species of jaegers, as the skuas of North America are known. Related to gulls and terns and best known for their predatory feeding habits, jaegers have circumpolar distribution, breeding in the Arctic and wintering in the southern hemisphere. A fourth skua species, the Great Skua, is principally found in Antarctica and the sub-antarctic islands with a separate population in the eastern North Atlantic.
The Parasitic Jaeger or Arctic Skua is the commonest of the jaegers in Manitoba and occurs in two colour phases. Light phased birds have white bodies and brown wings while dark phased birds are uniformly greyish brown. The Pomarine Jaeger is the largest of the three species and is also found in the two colour phases. The Long-tailed Jaeger, which is the smallest of the three and found almost exclusively

* Current address: 9 Jomar Avenue, R.R. \#2, Pickering, Ontario. L1V 2P9 